\title{
Defining pharmacy and its practice: a conceptual model for an international audience
}

This article was published in the following Dove Press journal:

Integrated Pharmacy Research and Practice

12 May 2017

Number of times this article has been viewed

\section{SL Scahill' \\ M Atif ${ }^{2}$ \\ ZU Babar ${ }^{3,4}$}

'School of Management, Massey Business School, Massey University, Albany, Auckland, New Zealand; ${ }^{2}$ Pharmacy School, The Islamia University of Bahawalpur, Bahawalpur, Pakistan; ${ }^{3}$ School of Pharmacy, University of Huddersfield, Huddersfield, England, UK; ${ }^{4}$ School of Pharmacy, Faculty of Medical and Health Sciences, University of Auckland, Auckland, New Zealand
Correspondence: SL Scahill

School of Management, Massey Business School, Massey University, Dairy Flat Highway (SHI7), Albany 0632, Auckland, New Zealand

Email s.scahill@massey.ac.nz
Background: There is much fragmentation and little consensus in the use of descriptors for the different disciplines that make up the pharmacy sector. Globalization, reprofessionalization and the influx of other disciplines means there is a requirement for a greater degree of standardization. This has not been well addressed in the pharmacy practice research and education literature.

Objectives: To identify and define the various subdisciplines of the pharmacy sector and integrate them into an internationally relevant conceptual model based on narrative synthesis of the literature.

Methods: A literature review was undertaken to understand the fragmentation in dialogue surrounding definitions relating to concepts and practices in the context of the pharmacy sector. From a synthesis of this literature, the need for this model was justified. Key assumptions of the model were identified, and an organic process of development took place with the three authors engaging in a process of sense-making to theorize the model.

Results: The model is "fit for purpose" across multiple countries and includes two components making up the umbrella term "pharmaceutical practice". The first component is the four conceptual dimensions, which outline the disciplines including social and administrative sciences, community pharmacy, clinical pharmacy and pharmaceutical sciences. The second component of the model describes the "acts of practice": teaching, research and professional advocacy; service and academic enterprise.

Conclusions: This model aims to expose issues relating to defining pharmacy and its practice and to create dialogue. No model is perfect, but there are implications for what is posited in the areas of policy, education and practice and future research. The main point is the need for increased clarity, or at least beginning the discussion to increase the clarity of definition and consistency of meaning in-and-across the pharmacy sector locally, nationally and internationally. Keywords: defining pharmacy, global standardization, conceptual model, normative practices

\section{Introduction}

The aim of this article is to identify and define the various subdisciplines of the pharmacy sector and integrate them into an internationally relevant conceptual model based on narrative synthesis of the literature. It is expected that significant dialogue will be derived from this article, and it is expected that it will provide a platform for moving forward in international pharmacy education. This is important because there is much fragmentation and little consensus in the use of descriptors for the different disciplines that make up the pharmaceutical sector. Globalization, reprofessionalization and the influx of other disciplines means there is a requirement for a greater degree of standardization. This has not been well addressed in the pharmacy practice research and education literature. 
Pharmacy education can be broadly divided into four areas: 1) pharmaceutics (sometimes labeled as pharmaceutical technology) and pharmacokinetics, 2) pharmaceutical chemistry, 3) pharmacology and 4) pharmacy practice includes clinical pharmacy, pharmacotherapy, social and administrative sciences, and pharmaceutical care. These subparts of the fourth category are often aggregated in a disparate manner. The first three categories are closely aligned with the basic sciences; the fourth category is inclusive of the human sciences. This fourth category has greater ambiguity, at least from the stance of definitions. ${ }^{1}$ Internationally, social and administrative pharmacy, clinical pharmacy, pharmaceutical care and pharmacy practice are terms used to describe different aspects of pharmacy practice. ${ }^{1-7}$ However, these terms have a level of subjectivity and mean different things to different people.

There is an emergent literature on the field of social pharmacy $^{8-15}$ and particularly in terms of education. ${ }^{16-22}$ There is a literature that defines pharmaceutical care s,23-26 $^{5}$ with some focus on community pharmacy. ${ }^{27-30}$ Similarly, there is a dialogue on what constitutes clinical pharmacy and how this relates to pharmaceutical care, ${ }^{31-33}$ but there is no model which defines these concepts and draws them together as a whole. ${ }^{34-36}$ Even between the proponents of the closely related concepts of social pharmacy and pharmacy practice, there is a lack of consensus on the research agendas for each subdiscipline and a call for a systematic analysis of this and further dialog. ${ }^{1-4,6,7,32} 33,37,38$ Equally, translational research - that is taking bench to bedside (and the reverse) is increasingly blurring the lines between what is considered "hard science" and what is deemed to be "soft practice". In fact, "the sciences" fit under the umbrella of pharmaceutical practice, and we argue that these basic sciences should be part of a conceptual model of what it is to be "pharmacy".

This article posits a model of pharmaceutical practice, which includes the professional practice activities of pharmacist clinicians. The term is distinct and has less controversial connotations than many others used interchangeably. The model also considers the broader roles undertaken by pharmacists, such as involvement in the development of health policy. The model incorporates the influx of significant others (sociologists, psychologists, etc.) into the academic discipline of pharmacy, and the roles that these groupings have and the contribution of their work to pharmaceutical practice. ${ }^{37}$ These roles are seen as a series of distinct disciplines within the conceptual model, but are at times blurred and have the potential to influence each other. The model outlines a conceptual approach to redefining the labels attached to these various disciplines, but also the practices of pharmacy within each of these. Absolute consensus of a model like this is near impossible, with the overlap and conflation of the different disciplines being difficult to unpack. What is possible though is an increased level of international dialogue and a drive toward a greater level of consistency than is currently seen. This is a theoretical framework, a beginning!

Alignment between real-world practice and academic pharmacy is thought about and melded into the model. It is expected that this will be an evolving conceptual model informed by the history of research and international commentary surrounding this topic.

\section{The need for a global model}

The need for a global conceptual model stems from the series of issues given below:

\section{Reason I - different things to different people: multiple definitions}

It is generally accepted that the disciplines of pharmaceutical science are founded on the basic sciences. Pharmaceutics, pharmaceutical chemistry, pharmacology and pharmacokinetics are well-established subdisciplines of the pharmaceutical sciences. The same cannot be said for new evolving clinically oriented disciplines. Even in these relatively circumscribed areas of pharmacy theory and practice, there is a significant divergence in opinion of what constitutes each and how, where and why these terms overlap. ${ }^{1,3,4,32,33,39,40}$ Clinical pharmacy, pharmacy practice, community pharmacy, retail pharmacy, social pharmacy and translational research are all likely to mean different things to different people.

In the area of hospital pharmacy, the terms pharmacy practice, clinical pharmacy, pharmacotherapy and public sector pharmacy have all been used interchangeably. Descriptions for community pharmacy have included pharmacy practice, retail pharmacy, community pharmacy, private sector pharmacy, private sector hospital pharmacy and clinical pharmacy practice in community pharmacies. ${ }^{1}$

Social and administrative pharmacy is used loosely to describe a collection of different interests, which outline the social aspects of pharmacy, sometimes labeled social pharmacy, other times administrative pharmacy but also pharmacy management. The broad discipline is founded on the principles of social science and organizational theory and has as a central interest in the beliefs, values and behaviors that people display in relation to medicine use and society at the individual and organizational levels. ${ }^{1-3,36,38,41-43}$ In some Commonwealth countries such as the UK, New Zealand and Australia, pharmacy practice seems to identify with 
community pharmacy with social pharmacy being considered a part of this. However, in the USA, social and administrative sciences has developed as a completely separate discipline and this also seems to be the case in parts of Asia.

Different from, but linked to, definitional difference is the idea that laws affecting practice will be different around the globe, and this means that it is more difficult to develop a consistent approach to interpreting practice-based definitions. Although the model may be limited by this, there is an expectation that the context will determine how the model is applied in different countries and the overall assumptions and basic reasoning for the model apply globally - the need for further dialogue in this area certainly applies on an international scale! Furthermore, people can take from the model what they wish and apply it locally!

\section{Reason 2 - the trend of clinical pharmacy and the Pharm D "tag"}

Clinical pharmacy is an important discipline in the practice of pharmacy - it has a lot to offer and has played an important role in transformation of the pharmacy profession over the past two decades. Clinical pharmacy has been part of the "re-professionalization" agenda both within the hospital and community sectors. ${ }^{16,44-47}$ However, there are many definitions of clinical pharmacy, and the term "clinical pharmacy" has been understood differently across the globe. Some relate it to "patient care", whereas others associate it more with the "managing appropriate use of medicines". 32

Amid these discussions in the developed world, the change has also greatly affected the pharmacy sector in developing countries, where establishing "clinical pharmacy" programs is considered a novel phenomenon. Under this influence, pharmaceutical care is popular jargon with the basic undergraduate pharmacy degrees having been changed to Doctor of Pharmacy (Pharm D) and the number of years of study simply extended in expectation of that. ${ }^{48}$ It would appear that pharmacy schools across Asia and within the Middle East are joining the "bandwagon" to promote clinical pharmacy. ${ }^{1}$ These countries are re-adjusting their degree programs by introducing Pharm D degrees as entry level qualifications into pharmacy. In some countries, in particular, "clinical pharmacy" is evolving in a very interesting manner. For example, in Pakistan, there was no separate discipline of clinical pharmacy, which is being taught under the umbrella of pharmaceutics in some universities. However, recently a new pharmacy practice discipline has been established. Anecdotal evidence also suggests that tensions and rifts between pharmacy and pharmacology colleagues have occurred.
Pharmacologists believe that they should teach clinical pharmacy programs. The pharmacologists' rationale is that clinical pharmacy is close to their domain, pharmacology being the study drug action on the body.

In Western countries, clinical pharmacy is established only when a stable medicine system is in place in the hospitals and drug regulatory authorities are mandated and efficient. Most developing countries do not have this luxury and are struggling with the issues of quality, safety, efficacy and distribution of medicines. ${ }^{49}$ In this context, clinical pharmacy is promoted as an isolated concept of practice and the underpinning philosophies are poorly understood and little has changed in terms of patient care. ${ }^{2}$

\section{Reason 3 - passionate and motivated by our individual subdisciplines}

Academics and practitioners see their discipline as central; yet, the literature is scarce when considering the pharmacy profession as a whole. Ahmed et al recognize these differences and suggest that a strong need exists to definitions relating to clinical pharmacy and pharmaceutical care. ${ }^{31}$ These standard definitions must be agreed upon and disseminated globally so that they are understood clearly (ie, clinical pharmacy and pharmaceutical care). This needs to be the case not only for pharmacists but also for other healthcare professionals and the wider disciplines, such as sociology and psychology. And, in this article, we take the work of Ahmed et al one step further and expand the need to develop a much broader model for pharmacists, other healthcare workers, government policy-makers and educators to take a sectorwide approach. ${ }^{31}$

\section{Reason 4 - what it is to be "pharmacy"}

In our experience and through anecdote, a question that is commonly fielded from key stakeholders (patients, public and other health professionals) is "what is pharmacy about?"; "what is it you do as a pharmacy profession - do you just count pills?" How then do we explain to colleagues and external stakeholders what we actually do, what our potential is as a profession and what our teaching encapsulates and what our research is all about? How in the broadest sense do we explain what pharmacy aims to contribute to health outcomes and further, how it might do so? We have a lot of different terminologies to describe ourselves as the pharmacy profession. We might say we work in the area of pharmacy practice, clinical pharmacy or social and administrative sciences. Importantly, medicines are not singularly the domain of pharmacists, and there is a need to help other nonpharmacy 
disciplines to understand what constitutes the pharmacy sector by standardizing terminology. In this way, it will also be easier to fit with policy, or at least integrate with and be understood by policy-makers and clinician stakeholders.

Part of the confusion and fragmentation surrounding the pharmacy profession comes from the overlap in "what we do" and "how we do it" but also how we label "who we are" and "what we do". For example, translational research is where basic and clinical sciences collide, cutting through boundaries between the research bench and patient bedside, empiric knowledge and soft practices. This creates an inherent blurring in what is deemed to be pharmaceutical science and what is deemed to be "clinical practice"; at least, this is the case from an academic viewpoint. Pharmacy practice and social pharmacy are also loose and slippery concepts to define, less so pharmaceutical care. Again the boundaries are blurred, but there is a need to put a stake in the ground and define these concepts so that things are more concrete.

The pharmacy sector is evolving and with the influx of significant others (such as sociologists, psychologists, anthropologists, historians, health economists, organizational and political scientists) into pharmacy academia and practice, the boundaries of the sector as a whole seem to have been extended and strengthened. For example, sociologists can conceptualize and operationalize research and practice that contribute significantly to introducing various behavioral models to the understanding of medicines use, thereby improving health outcomes. Research around pharmaceutical policy development and implementation, access to medicines and their use and pharmacoepidemiology are good examples of this type of work.

\section{Summary of the need for a conceptual model}

The definition of what constitutes "the pharmacy sector" and disciplines and practices thereof can be defined as broadly or as narrowly as one wishes. A narrow approach would feature the traditional elements of pharmacy, namely source and supply within a professional and regulated distribution model. ${ }^{44-47}$ Conversely, a broad conceptual stance would adopt elements from social and basic sciences as well. ${ }^{45}$ Either way a model is required, which redefines the pharmacy sector and the practices involved within the sector, both academic and professional. The model cuts through the current loose and interchangeable use of terminology and is founded on robust theoretical grounds. The authors' own insights and experiences are also infused into the model, which has developed in an organic fashion. ${ }^{50}$
This conceptual model is founded on the notion of consistency in definitions with respect to both the dimensions of the model and the model as a whole. The literature is scarce in describing the pharmacy sector "as a whole" and there are no "think piece" frameworks in this way. The main implication of the proposed model for theory is the call for clarity about the various parts of the pharmacy sector and how as a profession these dimensions may fit together.

\section{Pharmaceutical practice: a conceptual model}

Underpinned by the context previously outlined and with the need firmly established, we posit the term "pharmaceutical practice" and the associated conceptual model, which underpins this notion (Figure 1). The idea is that pharmaceutical practice encompasses everything, which is related to availability of medicines, access and use at the individual and the population levels. This term encapsulates the research, development, formulation, distribution, access and clinical use of medicines. It incorporates the human capital required to deliver pharmacy services and the impact on end users of pharmaceutical products and services.

\section{The dimensions: the glue making the whole Dimensions of disciplines}

Social and administrative sciences, community pharmacy, clinical pharmacy and pharmaceutical sciences are the dimensions of our conceptual model, and a description of each of the dimensions is outlined below.

\section{Social and administrative sciences}

The field of social pharmacy developed initially within highincome countries, including Scandinavia, Finland, the UK and the USA. ${ }^{45}$ More recently, there has been interest from academics in low- to middle-income countries and these groups have made significant contributions to this field. ${ }^{1,3,31}$ The International Social Pharmacy Workshop (ISPW) has been a foundation platform for the development of the research and practice networks within the discipline of social and administrative sciences. There are subtle differences between each workshop; however, the focus has been on research directed toward pharmaceutical policy, access to medicines, medicine use and pharmacoepidemiology, pharmacoeconomics, organizational behavior and individual pharmacist practice.

There are pockets of academics particularly passionate about the field of social pharmacy. Norris highlighted the challenges that the discipline of social pharmacy faces. ${ }^{37}$ Hassali et al have suggested social pharmacy as a field of study with a particular focus on the needs and challenges in 


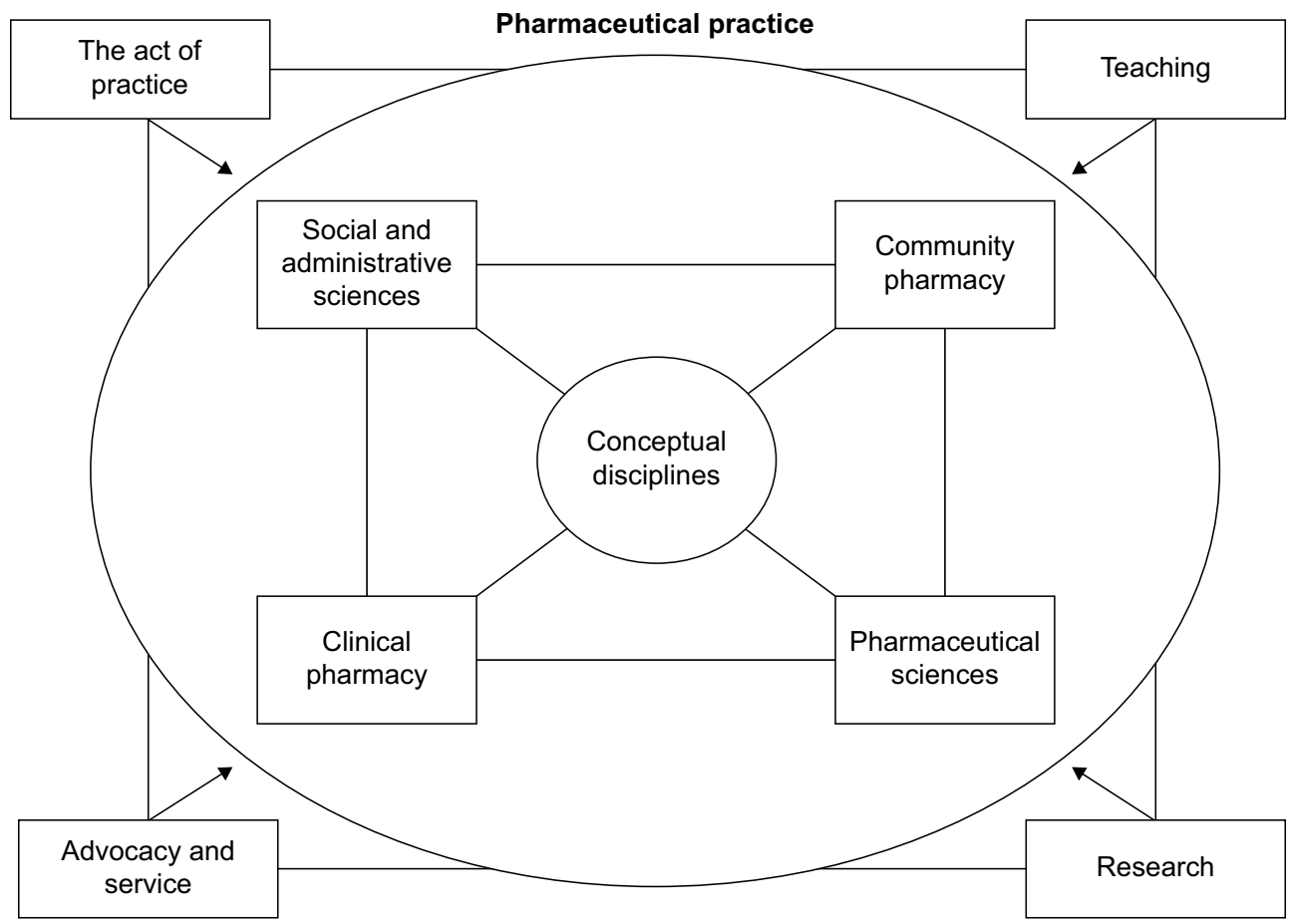

Figure I A conceptual model for pharmaceutical practice.

global pharmacy education. ${ }^{3}$ However, we believe that social pharmacy is an important part of the broader construct of pharmaceutical practice but is not the central umbrella concept - it is one of the four main dimensions. What are the other three?

\section{Community pharmacy}

Found within primary care, the practice of community pharmacy is reasonably clear cut at least with respect to its dual nature, as retailer and as primary healthcare provider and its separation from the rest of the profession. ${ }^{51}$ There seems to be a number of "labels" applied to this aspect of pharmacy, including community pharmacy, retail pharmacy, private sector pharmacy and corporate pharmacy. Despite significant differences in service delivery models, we see community pharmacy as a collective form of practice centered on an organization embedded within a community. Although much activity is undertaken in community pharmacy, there is a scarcity of research at the organizational level. ${ }^{42}$

\section{Clinical pharmacy}

Clinical pharmacy is the term that is most commonly used in the context of hospital pharmacy, where the focus is on pharmacotherapy and advanced subspecialties within this sector. The development of the clinical discipline is best reflected through the professionalization of hospital pharmacy in the USA. ${ }^{44}$ Although clinical pharmacy could be deemed to be carried out in the setting of community pharmacy, in the proposed model, there is a clear distinction between advanced clinical practice in the primary (clinical advisory pharmacists), secondary and tertiary care sectors (hospital clinical pharmacists), and clinical activities that are undertaken within the four walls of a community pharmacy. Pharmaceutical care involves a defined process and warrants consideration as it crosses boundaries by being able to be implemented in hospital pharmacy and also in the context of advanced clinical practice in the community pharmacy setting. Essentially, this is a clinical pharmacy service. The term "pharmacotherapy" also introduces a level of ambiguity as the label describes a process that could be owned by any health professional who is considered to have training in the area; nurse practitioners and clinical pharmacists are two examples.

\section{Pharmaceutical sciences}

As with the label of community pharmacy, pharmaceutical science is a relatively clear cut and well-defined aspect of the model. Ambiguity in this aspect of practice emerges only when one thinks about the potential of pharmaceutical sciences as a platform for translational research; bench research to bedside clinical use and bedside clinical issues influencing research activities at the bench! This is where crossover at multiple levels creates an inherent "blurriness", which we believe the proposed model will help to manage. It 
is also an area where universities are attempting to develop expertise and differentiate themselves from competitors, such as contract research organizations.

\section{The act of practice}

The act of practice can be thought of as those normative practices, the activities that are underpinned by what the culture of the specific discipline suggests is "normal". ${ }^{52}$ Regardless of whether the practice is considered clinical pharmacy or community pharmacy, it will be underpinned by values and beliefs that drive normative behavior. ${ }^{52,53}$ These values and behaviors are expected to align with the concept of what it is to be "pharmacy" within the individual subdisciplines outlined in our model.

\section{Teaching}

Teaching will vary dependent on the models of pharmacy that are practiced in any one country. However, the "labels" for each of the subdimensions of our model should be used in the same manner to describe the normative practices undertaken and the manner in which these practices are taught, regardless of country. That is, despite there being different needs in individual countries, the nomenclature/terminology being used should be broadly the same. The meaning of a definition in one country should be the same as in the next, despite slight variations in practice. The context may change but the meaning should not.

\section{Research}

Research underpins practice, and practice can also inform research questions. There is a potential research agenda that could be developed based on questions and issues raised by this model. This agenda is outlined as part of the implications of our model, found later in this modeling paper.

\section{Service - advocacy, professional sector development and} academic enterprise

Service and advocacy is an act of practice that does not appear as part of other models in the literature or dialogue about what constitutes a particular discipline. Essential to the model, this act of practice describes professional leadership. The absence of this is a possible contributor to the lack of voice and recognition of pharmacy's global role and the reason that pharmacy may be marginalized. ${ }^{54,55}$ As such, we believe this is an important and integral aspect of any pharmaceutical practice model as is the leadership, which underpins the model. ${ }^{55}$
The importance of local context in an international world

The individual dimensions of the pharmacy sector and their associated practices are influenced by local context. The proposed model takes this into consideration. There is a potential for tension between the viewpoints of those who call for curriculum development based wholly on local need analysis, alongside those who take the stance that "offthe-shelf" standardized degree programs from universities located in high-income countries is the optimal approach. ${ }^{56}$ The proposed model allows for both, however, but under the proviso that there is standardization in the use of terminology.

\section{International consistency: implications for policy, practice and research}

The proposed conceptual model calls for a contemporary "rethink" about what constitutes the pharmacy sector in today's terms. ${ }^{45}$ Historical review suggests that the pharmacy profession has changed over the past 100 years and considerably over the past few decades. This has occurred mostly in the context of high-income countries. ${ }^{45}$ However, through migration and technology, the world is becoming an increasingly small place. In general, there has been a lag in pharmacy education and practice change within low- to middle-income countries, which are now playing "catch up", and there are significant implications of the proposed model, which takes a global perspective. ${ }^{57}$ This is not the case for all developing countries and there are examples such as Thailand with a long and strong tradition of social pharmacy and advocacy around medicines regulation, which many in high-income countries could learn from.

\section{Implications for policy}

The proposed model has implications for educational policy and practice. The first implication is that this model provides a level of consistency with respect to the different dimensions within the pharmacy sector and the associated practices that relate to these. Therefore, it should be clear to educational and medicine-related policy-makers what the different aspects of the pharmacy sector represent, regardless of country context. In this way, resultant policy is able to be more uniform and ideally could be shared within and across countries. At least this is a starting point, a platform by which to develop locally relevant policy. Furthermore, intercountry comparisons of policy interventions could be undertaken; there is a dearth of information in this area. 


\section{Implications for education and practice}

There is a level of globalization occurring within pharmacy education and in pharmacy practice circles, with the drift of pharmacists from low- to high-income countries on the increase ${ }^{56}$ For countries that contribute to the "export market" of pharmacists from low- to high-income countries, there will be a need for terminology and definitions that have the same broad meaning within and across these countries. This will also be necessary in those countries that are not contributing to the pharmacist export market, but are publishing practice policy, guidelines or research.

The word "practice" is conceptualized as the "act of doing" 52 and each of the four dimensions that constitute the pharmacy sector have an associated practice. With a conceptual model such as this, the act of practice can be better defined within each of the aspects that make up the pharmacy sector, they being community pharmacy, clinical pharmacy, social and administrative sciences and pharmaceutical science.

\section{Implications for a future research agenda}

The proposed model of what constitutes the pharmacy sector provides a platform for standardization of pharmacy concepts and ideologies and defines these in a clear manner. The aim is to significantly reduce the ambiguity associated with the labeling what we do in pharmacy; however, it is simply a starting point. There is a need to conduct an international survey (as part of a justification process) among a large number of pharmacy leaders around the globe and others concerned, and then to present any amendments to this model. Facilitation of the survey could occur through the use of established international networks, such as ISPW, Pharmaceutical Care Network Europe or International Pharmaceutical Federation. The finalized model could then provide guidance for action with respect to policy development and implementation, practice and future research.

The proposed model was developed because of a perceived need to reduce the fragmentation and confusion that lies within the various subdisciplines of the pharmacy sector and to provide a starting point for discussion, which might help to unify the sector. A significant and well-informed research agenda is able to be developed by thinking about the different aspects of the proposed model. The model could be used to explore gaps in policy, practice and research across the four aspects of the pharmacy sector within and across high-, low- and middle-income countries.

\section{Conclusion}

Through this article, we bring up a very relevant issue and suggest a solution by presenting a conceptual model, which is quite a challenge. There is a definite need for clarifications and international standardizations of different aspects of pharmacy because of the various interpretations both within and between countries. To what extent practicing pharmacists, university professors, researchers and policy-makers agree with our interpretations and our division of conceptual disciplines and facets is less relevant than the thought provoked and the dialogue generated.

The article addresses the high level of fragmentation associated with labels applied to the various disciplines within the pharmacy sector. This model takes due care in outlining highlevel reasons for why this model is required, which include the following: discipline labels meaning different things to different people, the upward trend of clinical pharmacy, passionate and motivated drivers for subdisciplines and what it means to be part of the pharmacy sector. The model itself is fit for purpose across multiple countries and includes two components of an umbrella term labeled "pharmaceutical practice". The first component is the four conceptual dimensions, which outline the disciplines including social and administrative sciences, community pharmacy, clinical pharmacy and pharmaceutical sciences. The second component of the model describes the facets of the "act of practice": teaching, research and professional advocacy. This overarching model is expected to provide a platform for further dialogue in the move toward consistency and rationalization of terminologies, which describe the global pharmacy sector. There are implications of this work for policy, education and practice, the main point being increased clarity, or at least beginning the discussion to increase the clarity of definition and consistency of meaning in and across the pharmacy sector locally, nationally and internationally. Finally, a think piece of this nature throws up as many questions as it attempts to answer and it is expected that multicountry comparisons could be made based on such a model.

\section{Disclosure}

The authors report no conflicts of interest in this work.

\section{References}

1. Babar ZUD, Jamshed S. Social pharmacy strengthening clinical pharmacy: why pharmaceutical policy research is needed in Pakistan? Pharm World Sci. 2008;30(5):617-619.

2. Almarsdóttir AB, Kaae S, Traulsen JM. Opportunities and challenges in social pharmacy and pharmacy practice research. Res Soc Admin Pharm. 2014;10(1):252-255.

3. Hassali MA, Shafie AA, Al-Haddad MSD, et al. Social pharmacy as a field of study: the needs and challenges in global pharmacy education. Res Soc Admin Pharm. 2011;7(4):415-420.

4. Hepler CD, Strand LM. Opportunities and responsibilities in pharmaceutical care. Am J Hosp Pharm. 1990;47(3):533-543.

5. Penna RP. Pharmaceutical care: pharmacy's mission for the 1990s. Am J Health-System Pharm. 1990;47(3):543-549.

6. Van Mil J, Schulz M. A review of pharmaceutical care in community pharmacy in Europe. Harvard Health Pol Rev. 2006;7(1):155-168. 
7. Van Mil JF, Schulz M, Tromp TFD. Pharmaceutical care, European developments in concepts, implementation, teaching, and research: a review. Pharm World Sci. 2004;26(6):303-311.

8. Anderson C. Social pharmacy: the current scenario. Indian J Pharm Pract. 2008;1:1-5.

9. Gerrett D, Stevenson F. A dilemma for "social" pharmacy practice research. Int J Pharm Pract. 1995;3(2):65-67.

10. Harding G, Taylor K. Defining social pharmacy: it needs its own distinct identity. Int J Pharm Pract. 1993;2(2):62-63.

11. Harding G, Taylor K. Social Pharmacy: Innovation and Development. London: Pharmaceutical Press; 1994.

12. Meng R, Liu T. Discussions on social pharmacy and pharmacy administration. Pharm Educ. 2004;3:005.

13. Palaian S, Poudel A, Alam K, Ibrahim MIM, Mishra P. Initiation of social pharmacy research in Nepal: our experiences. Int J Clin Pharm. 2011;33(4):591-596.

14. Van der Geest S, Whyte SR. The Context of Medicines in Developing Countries: Studies in Pharmaceutical Anthropology: Het Spinhuis. The Netherlands: Kluwer Academic Publishers; 1991.

15. Wertheimer A. Social/behavioural pharmacy - the Minnesota experience. J Clin Pharm Therap. 1991;16(6):381-383.

16. Abrika OSS, Hassali MA, Abduelkarem AR. Importance of social pharmacy education in Libyan pharmacy schools: perspectives from pharmacy practitioners. J Educ Eval Health Prof. 2012;9:6.

17. Abrika OSS, Hassali MAA, Abduelkarem AR. Social pharmacy courses are often neglected in the developing world. Am J Pharm Educ. 2011;75(4):65b.

18. Anderson C, Bates I, Beck D, et al. The WHO UNESCO FIP pharmacy education taskforce. Hum Resour Health. 2009;7:45.

19. Ghani K, Gillani W, Ghani M. Pharmacy teaching and practices problems in developing countries: review. Int $J$ Pharm Teach Pract. 2010;1(1):11-17.

20. Harding G, Taylor KM. Teaching social pharmacy: the UK experience. Pharm Educ. 2006;6(2):125-131.

21. Izham MI, Rahmat AD, Abdul Razak M. Introducing social pharmacy courses to pharmacy students in Malaysia. Med Teach. 1998;20(2): 122-126.

22. Schaefer M, Leufkens H, Harris M. The teaching of social pharmacy/ pharmacy administration in colleges of pharmacy with special regard to the situation in Germany. J Soc Admin Pharm. 1992;9(4):141-148.

23. Berenguer B, La Casa C, de La Matta M, Martin-Calero M. Pharmaceutical care: past, present and future. Curr Pharm Design. 2004;10(31):3931-3946.

24. Dupotey NMV, de Oliveira DR. A qualitative glimpse at pharmaceutical care practice. Pharm World Sci. 2009;31(6):609-611.

25. Martin-CaleroM,MachucaM,MurilloM,CansinoJ,GastelurrutiaM,FausM. Structural process and implementation programs of pharmaceutical care in different countries. Curr Pharm Design. 2004;10(31):3969-3985.

26. Roughead E, Semple S, Vitry A. Pharmaceutical care services: a systematic review of published studies, 1990 to 2003, examining effectiveness in improving patient outcomes. Int J Pharm Pract. 2005;13(1):53-70.

27. Eickhoff C, Schulz M. Pharmaceutical care in community pharmacies: practice and research in Germany. Ann Pharmacother. 2006;40(4): 729-735.

28. Farris KB, Fernandez-Llimos F, Benrimoj SC. Pharmaceutical care in community pharmacies: practice and research from around the world. Ann Pharmacother. 2005;39(9):1539-1541.

29. Van Mil JF. Pharmaceutical care in community pharmacy: practice and research in the Netherlands. Ann Pharmacother. 2005;39(10):1720-1725.

30. Westerlund LT, Björk HT. Pharmaceutical care in community pharmacies: practice and research in Sweden. Ann Pharmacother. 2006;40(6):1162-1169.
31. Ahmed SI, Hasan SS, Hassali MA. Clinical pharmacy and pharmaceutical care: a need to homogenize the concepts. Am J Pharm Educ. 2010;74(10):193g.

32. Franklin BD, van Mil J. Defining clinical pharmacy and pharmaceutical care. Pharm World Sci. 2005;27(3):137.

33. Hepler CD. Clinical pharmacy, pharmaceutical care, and the quality of drug therapy. Pharmacother. 2004;24(11):1491-1498.

34. Harding G, Taylor K. Towards a model of pharmacy practice research. Int J Pharm Pract. 1996;4(2):65-66.

35. Nosrgaard LS, Morgall JM, Bissell P. Arguments for theory based pharmacy practice research. Int J Pharm Pract. 2000;8(2):77-81.

36. Scahill $\mathrm{S}$. Involving community pharmacy services by studying organizational theory. South Med Rev. 2008;1(1):17-19.

37. Norris PT. Challenges facing social pharmacy. Res Soc Admin Pharm. 2009;5(3):195-196.

38. Scahill S, Babar Z. Social Pharmacy: borrowing tools and theories the world over. South Med Rev. 2011;4(1):1.

39. Hepler CD. Pharmaceutical care. Pharm World Sci. 1996;18(6):233-235.

40. Hepler CD, Grainger-Rousseau T-J. Pharmaceutical care versus traditional drug treatment. Drugs. 1995;49(1):1-10.

41. Ryan K, Bissell P, Anderson C, Traulsen JM, Sleath B. Teaching social sciences to undergraduate pharmacy students: an international survey. Pharm Educ. 2007;7(1):1-9.

42. Scahill SL. Placing "culture" at the center of social pharmacy practice and research. Res Soc Admin Pharm. 2013;9(1):1-3.

43. Sørensen E, Mount J, Christensen S. The concept of social pharmacy. Chronic. 2003;101(7):7.

44. Birenbaum A. Reprofessionalization in pharmacy. Soc Sci Med. 1982; 16(8):871-878.

45. Bissell P, Morgall-Traulsen J. Sociology and pharmacy practice. London: Pharmaceutical Press; 2005.

46. Gilbert L. Community pharmacy in South Africa: a changing profession in a society in transition. Health Place. 1998;4(3):273-285.

47. Gilbert L. Pharmacy's attempts to extend its roles: a case study in South Africa. Soc Sci Med. 1998;47(2):153-164.

48. Jamshed S, Babar ZUD, Masood I. The PharmD degree in developing countries. Am J Pharm Educ. 2007;71(6):125.

49. Garg S, Hasan R, Scahill S, Babar ZU-D. Investigating inspection practices of pharmaceutical manufacturing facilities in selected Arab countries: views of inspectors and pharmaceutical industry employees. East Med Health J. 2013;19(11):919-929.

50. Lincoln Y, Guba E. Naturalistic Inquiry. Newbury Park, CA: Sage; 1985.

51. Hibbert D, Bissell P, Ward PR. Consumerism and professional work in the community pharmacy. Sociol Health Ill. 2002;24(1):46-65.

52. Schein E. Organizational Culture and Leadership. San Francisco, CA: Jossey-Bass; 2004.

53. Cameron K, Quinn R. Diagnosing and Changing Organizational Culture. Reading, MA: Addison-Wesley; 1999.

54. Bissell P, Traulsen JM, Haugbolle LS. Sociological theory and pharmacy practice research: (1) An introduction to sociology — and what it can do for pharmacy practice research. Int J Pharm Pract. 2001;9(4): 289-296.

55. Scahill S, Harrison J, Sheridan J. The ABC of New Zealand's ten year vision for pharmacists: awareness, barriers and consultation. Int J Pharm Pract. 2009;17(3):135-142.

56. Babar Z-U-D, Scahill SL, Akhlaq M, Garg S. A bibliometric review of pharmacy education literature in the context of low-to middle-income countries. Curr Pharm Teach Learn. 2013;5(3):218-232.

57. Babar Z-U-D, Scahill S. Barriers to effective pharmacy practice in low-and middle-income countries. Int Pharm Res Prac. 2014;3:25-27. 
Integrated Pharmacy Research and Practice is an international, peer-reviewed, open access, online journal, publishing original research, reports, reviews and commentaries on all areas of academic and professional pharmacy practice. This journal aims to represent the academic output of pharmacists and pharmacy practice with particular focus on integrated care. All papers are carefully peer reviewed to ensure the highest standards as well as ensuring that we are informing and stimulating pharmaceutical professionals. The manuscript management system is completely online and includes a very quick and fair peer-review system, which is all easy to use. Visit http://www.dovepress.com/ testimonials.php to read real quotes from published authors.

Submit your manuscript here: http://www.dovepress.com/integrated-pharmacy-research-and-practice-journal 